\title{
Mid-Term Load Forecasting Based on Neural Network Algorithm: a Comparison of Models
}

\author{
Pituk Bunnoon
}

\begin{abstract}
This article purposes the model of mid-term energy consumption load forecasting (MTLF) by using artificial neural network based on the two and the three years ahead. This load demand forecasting is a useful tool for a unit commitment and a fuel reserve planning in the power system. Both two and three years ahead forecasting uses two patterns for comparing the accuracy in this research. The results show the two years ahead of load forecasting, model no.2 can be reduced error which Mean Absolute Percentage Error (MAPE) is $4.35 \%$. In three years ahead, the load forecasting model no.1 and no.2, MAPE are almost equal which are equal $4.65 \%$ and $4.70 \%$, respectively. Finally, the experimental results show two and three years ahead for the load forecasting by using differential models and a varies number of a neuron in the hidden layer for finding the minimum MAPE of each model.
\end{abstract}

Index Terms-Energy consumption; Forecasting; Neural network; Yearly ahead.

\section{INTRODUCTION}

Load forecasting has a very important in the power system such as energy consumption demand forecasting (ECDF) and peak load forecasting (PLF). It is a useful tool for a unit commitment and fuel reserve planning in power system. The load demand is depended many variables like industrial index, consumer price index, fuel price, salary index, money exchange, temperature, humidity, and wind speed.

Load forecast can be classified into four differential types. Very short term load forecasting have period time in a minute, it is importance for real time operation. Short-term load forecasting have period time in a minute to three months, it is importance for unit commitment and operation. Mid-term load forecasting have period time in three months to three years, it is importance for fuel reserve planning and unit commitment. Finally, Long- term load forecasting have period time in three years to not over fifteen years, it is importance for generation and power plant planning. In this research will offer the energy consumption demand forecasts. It is a very important for fuel reserve planning and unit commitment in power system.

Several forecasting methods have been implemented for load forecasting such as statistical methodology: time series, exponential smoothing, and autoregressive integrated moving average (Box-jenkins). For the present, there are many algorithms for load forecasting in the computation intelligence like fuzzy logic $[1,4-5,10-11,18]$, neural network

Manuscript received April 3, 2011; revised July 18, 2011.

Pituk Bunnoon is with Rajamangala University of Technology Srivijaya, 1 Radchadumniennok Road, Boyang, Songkhla, Thailand (Email: pituk.b@rmutsv.ac.th)
[1-7,10-12,14-15,18-21], genetic[5,10,19], support vector machine [13], and chaos[19].

Many research purposed the article for load forecasting in the power system field : short term load forecasting using autoregressive integrated moving average (ARIMA) and artificial neural network (ANN) method based on non-linear load [7], a novel method approach to load forecasting using regressive model and artificial neural network (ANN model) [6], the combination of artificial neural network (ANN), Genetic algorithm, and Fuzzy logic (Fs) method are proposed for adjusting short-term load forecasting of electric system $[5,19]$. Genetic algorithm is used for selecting better rules and back propagation algorithm is also for this network, papers show that more accuracy results and faster processor than other forecasting methods.

The factors are impacted including on the mid-term load demand: industrial index, consumer price index, temperature, humidity, rainfall, and wind speed variable. Economic variables are usually influenced to a trend component while weather factors are usually influenced to a cyclical component.

This research aims to develop a mid-term load forecasting for yearly energy consumption demand forecasting in Thailand. This forecast method uses neural network algorithm based on feed forward back propagation algorithm. Two years ahead load forecasting have two patterns model that are model no.1 and model no. 2 which have four inputs and twelve inputs, respectively. Three years ahead mid-term load forecasting have two patterns like model no. 1 and model no. 2 which have four inputs and four inputs, respectively. This research is focused on the pattern input before taking the feature inputs into neural network model.

This paper is organized as follows. In section II describes the energy consumption demand and variables. In section III presents artificial neural network. In section IV shows case study and test results. Finally, the conclusions are drawn in section V. All these contents will be presented in following.

\section{CONSUMPTION DEMAND AND VARIABLES}

The load demand as a function of time has a complex nonlinear behavior. It depends on a number of complex factors such as seasonal weather, and national economic growth [9].

\section{A. Energy Consumption Demand}

Monthly energy consumption demand (Unit in GWh) data is recorded form Electricity Generating Authority of Thailand (EGAT) from 1997 to 2007. Fig.1 shows the relationship between energy consumption demand and time series [9]. 


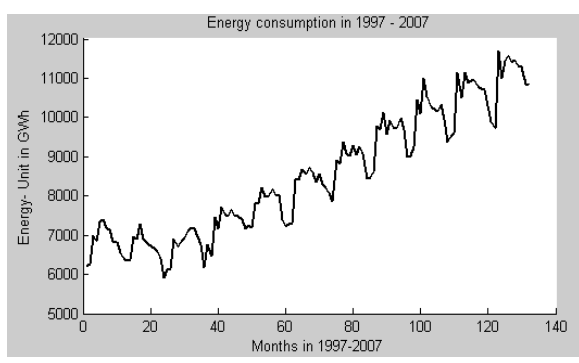

Fig. 1 Monthly Energy consumption demand of Thailand (GWh) recorded from January 1997 to December 2007 [9]

We consider the period from 1997 to 2007 to establish the parameters in forecast model. The original signal (behavior) of energy consumption demand can be seen in Fig.1. It grew the higher demand every year. The maximum demand is occurred on mid-year or between on March to June. Minimum demand is occurred between on December to January approximately.

\section{B. Variables correlation}

In the power systems, several influencing variables can be affected to the behavior of the energy consumption demand. The influence variables are the weather variables and the economic variables of the country. The weather variables have been affected in short-term, mid-term, and long-term load forecasting: maximum temperature, minimum temperature, humidity, rainfall, and wind speed. The economic variables have been affected in mid- term and long-term load forecasting: industrial index and consumer price index.

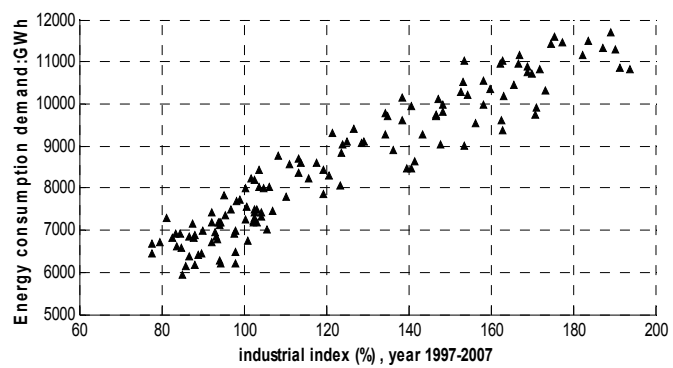

Fig.2 Relationship between energy consumption demand and industrial index

Fig.2 shows the relationship between the load demand and industrial index. The correlated value of these factors is $94.0 \%$. Fig. 3 shows the relationship between the load demand and consumer price index. The correlated value of these factors is $91.0 \%$.

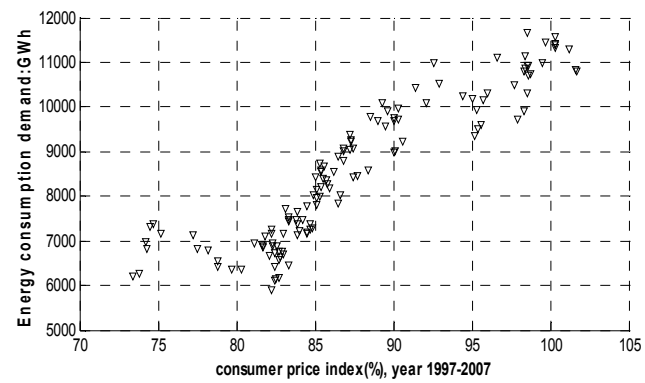

Fig.3 Relationship between energy consumption demand and consumer price index

Fig.4 shows maximum and minimum temperature of the country which is recorded from 1997 to 2007. Several influencing variables are not presented in this paper like humidity, rainfall, and wind speed of the country.

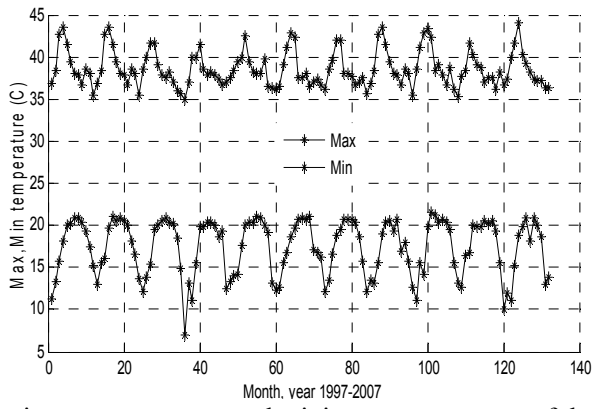

Fig.4 Maximum temperature and minimum temperature of the country

The summary of all variables correlation in this research can be seen in Table I. It shows the relationship between the load demand, maximum temperature, minimum temperature and other variable. The maximum value is industrial index. The minimum value is wind speed.

TABLE I: THE RELATIONSHIP BETWEEN LOAD DEMAND AND VARIABLES

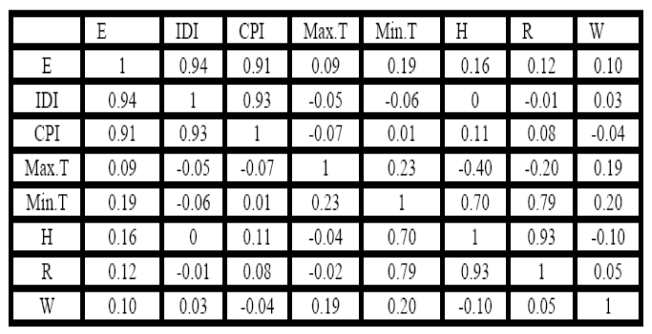

Note that, E is energy consumption demand, IDI is industrial index, CPI is consumer price index, Max.T and Min.T are maximum and maximum temperature, $H$ is humidity, $R$ is rainfall, $W$ is wind speed.

\section{ARtificial NEURAL NETWORK}

\section{A. Basic Theory-feed forward back propagation}

The neural network purposes in this paper. It has three-layers based on feed-forward back propagation algorithm (FFBP). The fundamental structure of this algorithm can be seen in Fig.5.

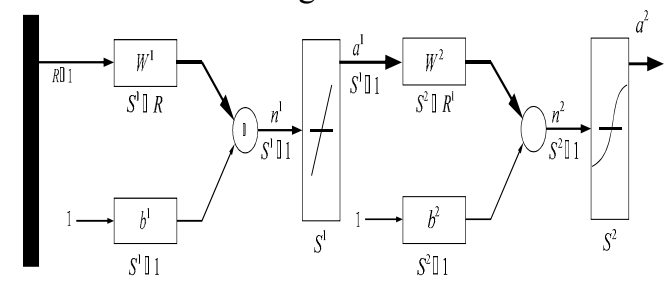

Fig.5 Structure of back propagation neural network [21]

In Fig.5, an artificial neural network consists of input layer, hidden layer, and output layer. It can be varied a hidden neuron for finding the optimal weight and bias before simulating or forecasting the load demand. The activation functions or transfer functions of the network in each layer can be shown as a simple in Fig. 6, where:

$$
a^{1}=f^{1}\left(W^{1} p+b^{1}\right)
$$

and

$$
a^{2}=f^{2}\left(W^{2} a^{1}+b^{2}\right)
$$

Finally, neuron output is

$$
a^{2}=f^{2}\left(W^{2} f^{1}\left(W^{1} p+b^{1}\right)+b^{2}\right)
$$

where $a^{1}, a^{2}$ are outputs in hidden layer, and output layer respectively? $W^{1}, W^{2}$ Are weights, $b^{1}, b^{2}$ is bias and $p$ is $R$ input. Fig.5, losing and prelim activation functions are used 
in this research.

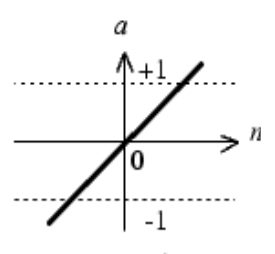

$a=\operatorname{purelin}(n)$

Fig.6 Activation transfer functions [8]

This research purposes neural network based on hidden layer and output layer transfer function: logsig and purelin transfer functions which are satisfied for the load forecasting research.

\section{B. Forecasting flow chart based on neural network}

The original signals can be normalized by using the following:

$$
N_{k}=\left\{\frac{k-\min }{\max -\min }\right\} \quad ; 0 \leq N_{k} \leq 1
$$

where $\mathrm{k}$ is value for normalize,

Min is minimum value,

Max is maximum value.

The outline of the procedure to build the neural network model is presented block diagram in Fig.7 and Fig.8. In summary, the main steps of this proposed energy consumption demand forecasting model as the following:

1) Many variables are selected from the database: temperature, humidity, wind speed, rainfall, industrial index, and consumer price index.

2) All input variables are transformed to relative differences.

3) All input variables are limited thought the correlation by using MATLAB or SPSS program

4) Each factor is normalized by using equation (4).

5) Definition of neuron in hidden layer, epoch, and goal of neural network.

6) Random initial weight and bias.

7) Compute the output based on feed forward back propagation algorithm and MSE by using equation (5).

8) Adjusts weight and bias.

9) Store weight and bias that compute minimum MSE.

10) The model simulates the program for forecasting with testing data and calculates MAPE by using equation (6).

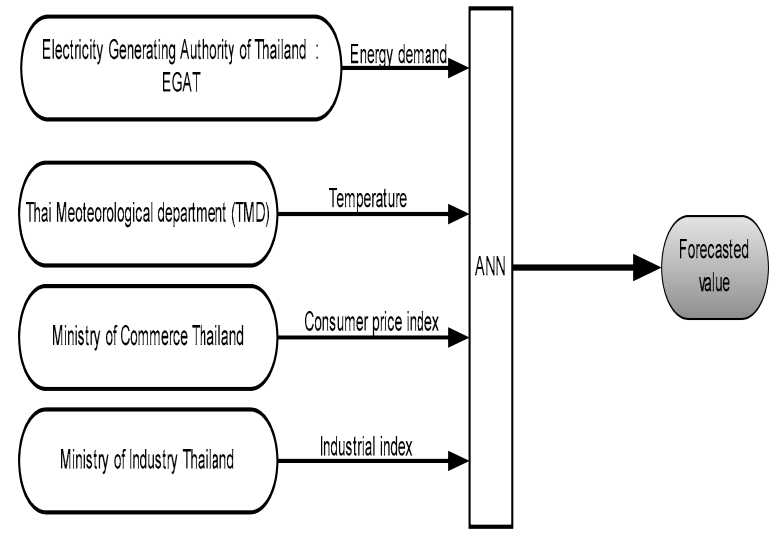

Fig.7 Block diagram for forecasting based on neural network

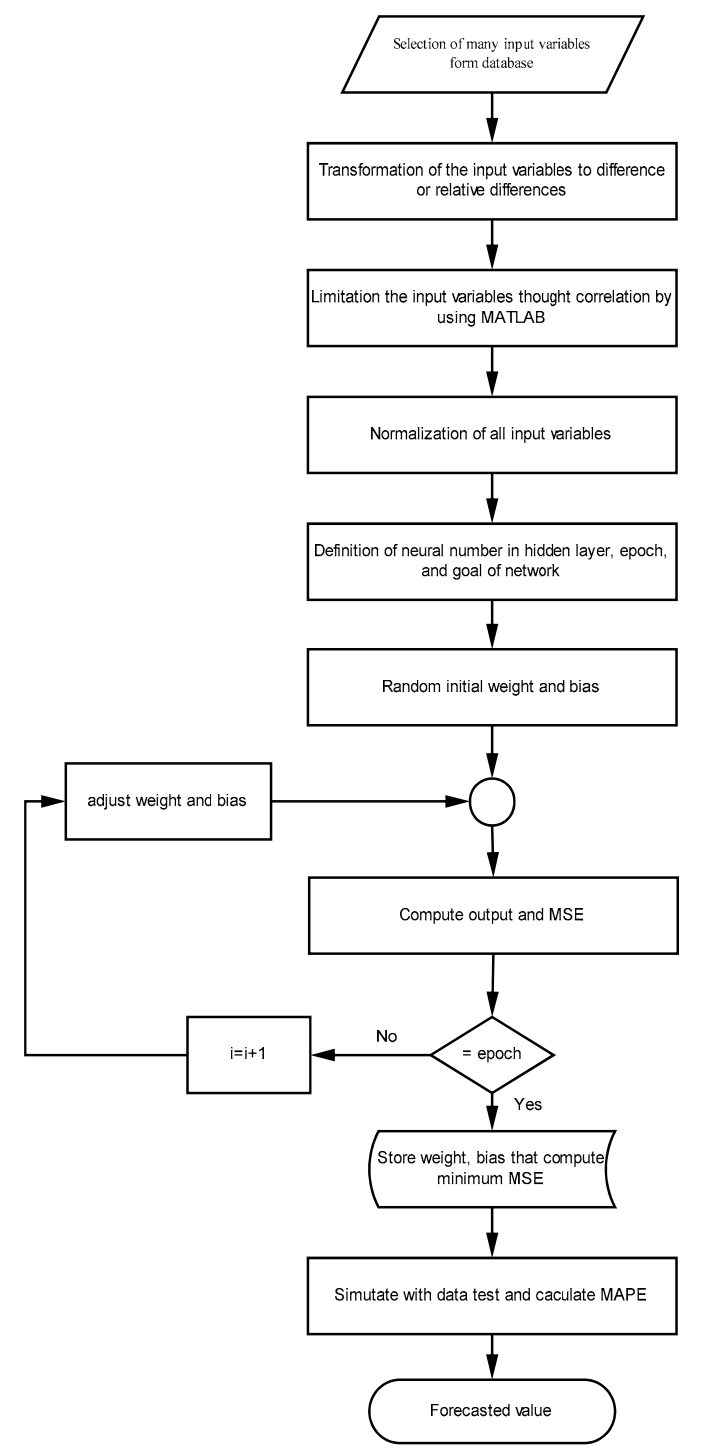

Fig.8 Flow chart of mid-term load forecasting using neural network

\section{Accuracy of Forecasted}

In order to evaluate forecasting accuracy of the whole procedure the following indices have been calculated (5-6) [9]:

Mean Square Error (MSE) for each month of forecastting:

$$
M S E=\sum_{i=1}^{M} \frac{\left(\text { Actual }_{[i]}-\text { Forecasted }_{[i]}\right)^{2}}{M}
$$

Mean Absolute Percentage Error (MAPE) give by:

$$
\text { MAPE }=\frac{1}{M} \sum_{i=1}^{M} \frac{\mid \text { Actual }_{[i]}-\text { Forecasted }_{[i]} \mid}{\text { Actual }_{[i]}} \times 100
$$

where Actual is the real value of monthly load demand at the itch year, Forecasted is the forecasted value in the same year, and $M$ is month.

\section{Case Study and Test Results}

In this paper, case study and test results will be present in this section by following:

\section{A. Case study}


This paper proposes the historical information or data for the load forecasting as following:

Monthly energy consumption demand $(G W h)$ is supported by Electricity Generating Authority of Thailand (EGAT). The Humidity $(H)$, Rainfall $(R)$, and Wind Speed $(W)$ are given from Meteorology Department of Thailand (TMD). Current Price Index (CPI) is informed by Ministry of Commerce Thailand. Industrial Index (IDI) including the forecasted values is given from Ministry of Industry Thailand. All of data information is recorded from 1997 to 2007 [9].

\section{B. Test results}

Fig. 9 and Fig.10 show the block model for two years ahead demand forecasting which have four inputs: the historical load demand from -12 months to -96 months, maximum temperature from 0 months to -84 months, consumer price index from 0 months to -84 months, and industrial index from 0 months to -84 months. These are feature inputs to artificial neural network. The output of this model is the load demand of the country that is +twenty-four months ahead or two years ahead. Not that, year 2005 (0), 2004 (-12), 2003 (-24), 2002 $(-36), 2001 \quad(-48), 2000(-60), 1999(-72), 1998(-84)$, and $1997(-96)$.

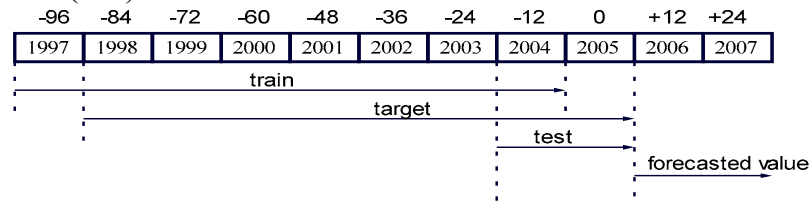

Fig.9 Model no.1 for two years ahead forecasting

The forecasted values by using model in Fig.9, 10 can be seen the results of two years forecasting in Fig. 11.

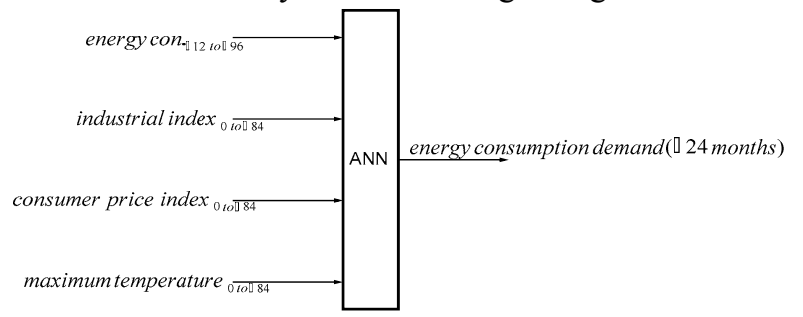

Fig.10 Two years ahead forecasting by model no.1

Fig. 11 (a) and (b) show the value of actual load demand in 2006 to 2007 on dash line. Solid line shows the forecasted values. The mean absolute percentage error (MAPE) is $6.51 \%$.
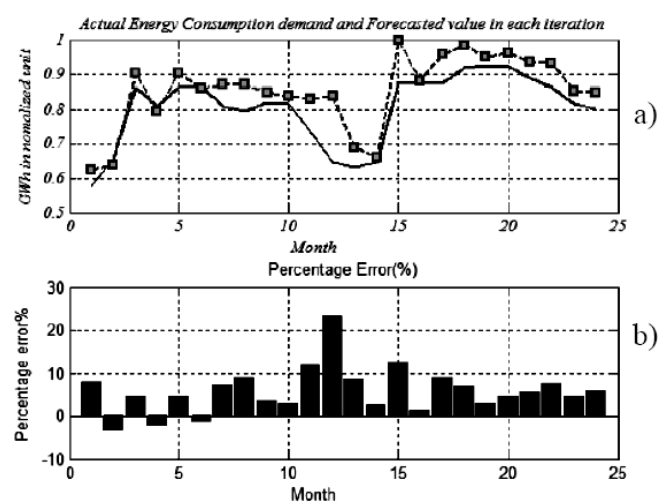

Fig.11 The results of two years ahead forecasting model

Fig.12 and Fig.13 show the block model for two years ahead load demand forecasting which have twelve inputs: energy con.i-1, energy con.i-2, energy con.i-3, industrial indexi-0, industrial indexi-1, industrial indexi-2, consumer price indexi-0, consumer price indexi-1, consumer price indexi-2, maximum temperaturei-0, maximum temperaturei-1, and maximum temperaturei-2. The output of this model is energy consumption demand of the country that is +twenty-four months ahead or two years ahead. Note that: year 2005 (0), 2004 (-12), 2003 (-24), 2002 (-36), 2001 (-48), $2000(-60), 1999$ (-72), $1998(-84)$, and $1997(-96)$.

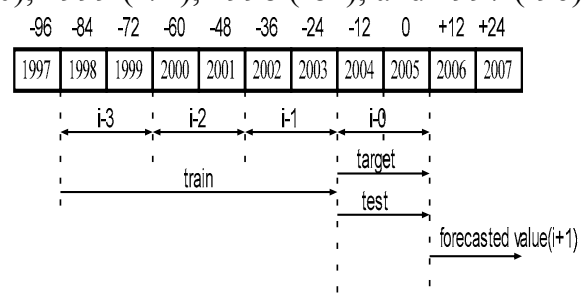

Fig.12 Model no.2 for 2 years ahead forecasting

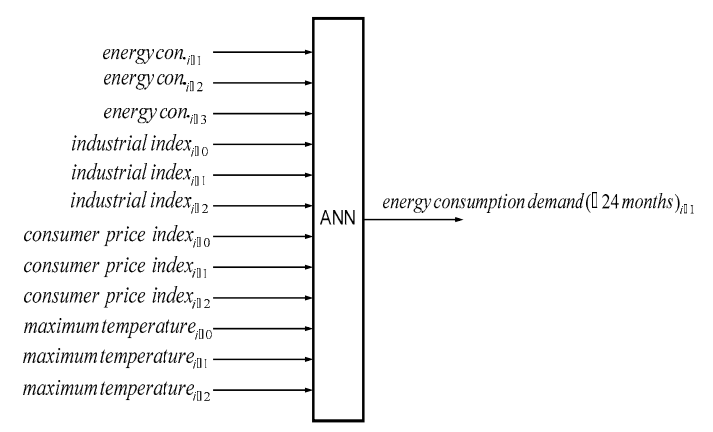

Fig. 13 Two years ahead forecasting by model no. 2

Fig. 14 (a) and (b) show the value of actual load demand from 2006 to 2007 on dash line. Solid line shows the forecasted values. The mean absolute percentage error (MAPE) is $4.35 \%$.
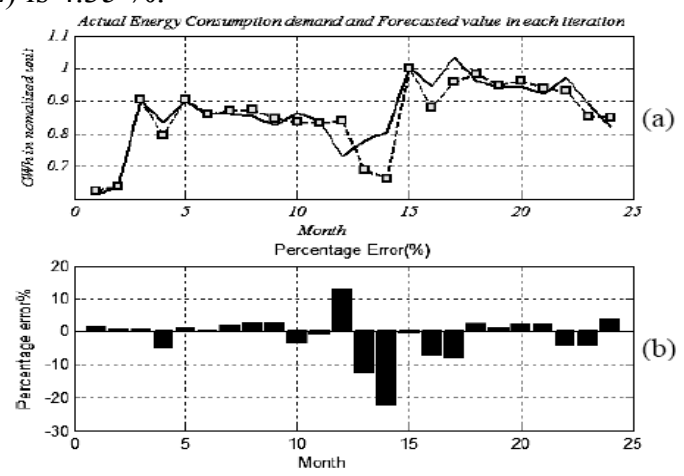

Fig.14 The result of two years ahead forecasting model

Fig.15 and Fig.16 show the block model for three years ahead the load demand forecasting which have four inputs: the historical of energy consumption demand from -12 to -84 months, maximum temperature from 0 to -72 months, consumer price index from 0 to -72 months, and industrial index from 0 to -72 months. The output of this model is energy consumption demand of the country that is +thirty-six months ahead or three years ahead. Note that: year $2004(0)$, 2003 (-12), 2002 (-24), 2001 (-36), 2000 (-48), 1999 (-60), $1998(-72)$, and $1997(-84)$.

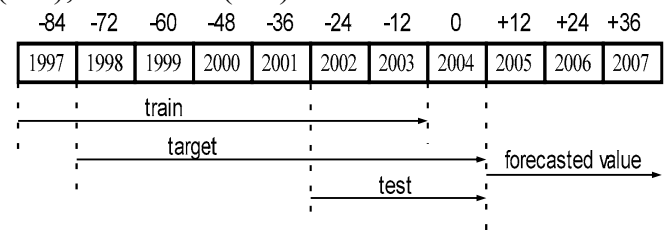

Fig.15 Model no.1 for 3 years ahead forecasting 


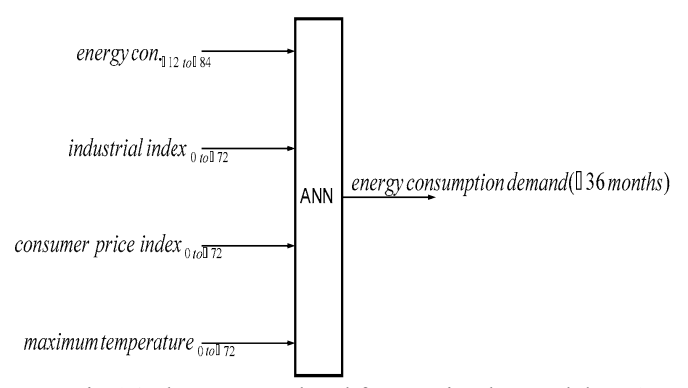

Fig.16 Three years ahead forecasting by model no.1

The forecasted value by using model in Fig. 15 and 16 can be seen the models and the results of three years forecasting in Fig.18. Table I show the actual load demand and forecasted value in each month.

Fig.17 (a) shows the actual load demand in 2005, 2006, and 2007 on dash line. Solid line shows the forecasted values. The mean absolute percentage error (MAPE) is $4.70 \%$. It can be seen the percentage error (PE) for each month in Fig.17 (b).
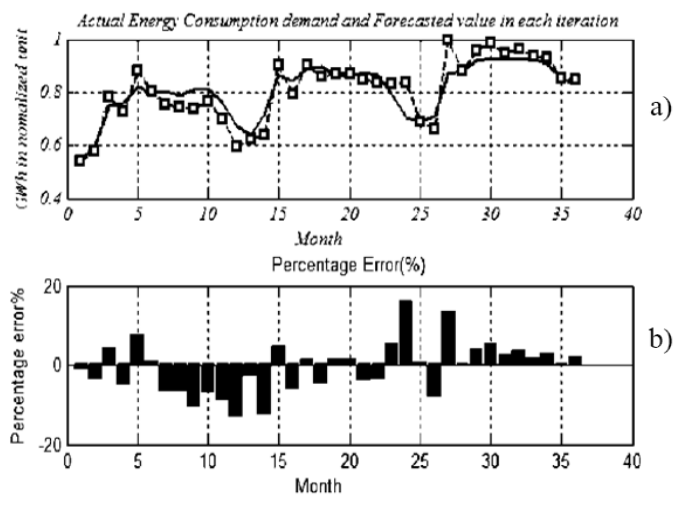

Fig.17 The result of three years ahead forecasting model

Fig.18 and Fig.19 show the block model for three years ahead load demand forecasting which have four inputs: energy con.i- 1 , industrial indexi- 0 , consumer price indexi- 0 , and maximum temperaturei- 0 . The output of this model is energy consumption demand of the country that is +thirty-six months ahead or 3 years ahead. Note that: year $2004(0)$, 2003(-12), 2002 (-24), 2001 (-36), $2000 \quad(-48), 1999(-60)$, $1998(-72)$, and $1997(-84)$.

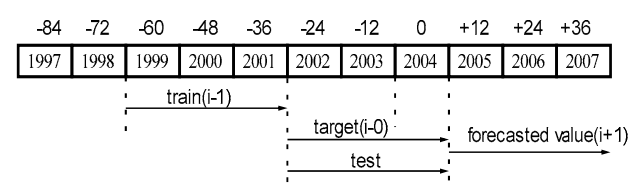

Fig.18 Model no.2 for 3 years ahead forecasting

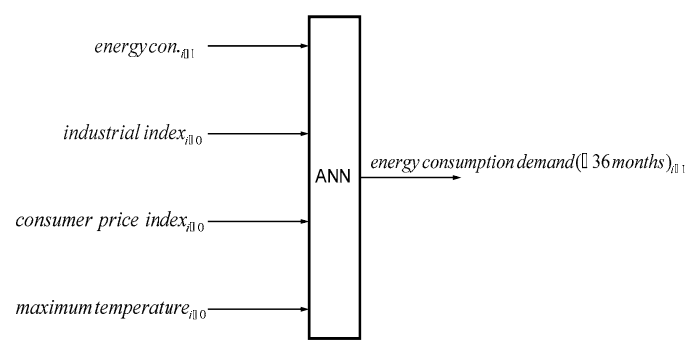

Fig.19 Three years ahead forecasting model by model no. 2

Fig.20 shows the actual load demand in 2005, 2006, and 2007 on dash line. Solid line shows the forecasted values. The mean absolute percentage error (MAPE) is $4.65 \%$. It can be seen the percentage error (PE) for each month in Fig.20 (b).
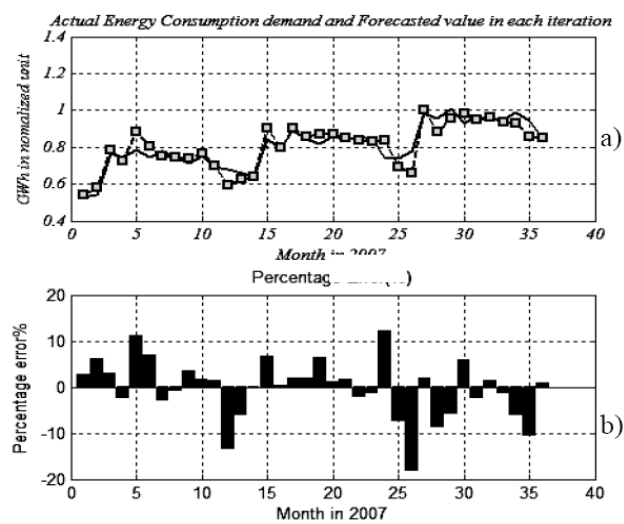

Fig.20 The results of three years ahead forecasting model

Fig.19 and 12 show the data information for training, target, and testing which are used for two years forecasting of the model no.1 and no.2. Fig. 10 and 13 show details of model no. 1 and no.2 based on neural network algorithm. Fig. 11 and 14 show results of these models. Fig. 15 and 18 show data information for train, target, and test which are used for three years forecasting of model no.1 and no.2. Fig. 16 and 19 show details of model no. 1 and no. 2 based on neural network algorithm. Fig.17 and Fig.20 show the results of these models.

TABLE II: on left-hand shows actual consumption demand and forecasted value error in 2005, 2006, and 2007 (three years); on right-and shows actual consumption demand and forecasted value error month in 2006, and 2007 (two years).

TABLE III: This table shows the result of energy consumption demand forecasting and varied number of neuron in hidden layer from five, ten, fifteen, twenty, twenty-five, and thirty neurons. The experimental results show mean absolute percentage error (MAPE) in this table.

TABLE II: ACTUAL AND FORECASTED LOAD DEMAND (NORM: UNIT IN GHZ.)

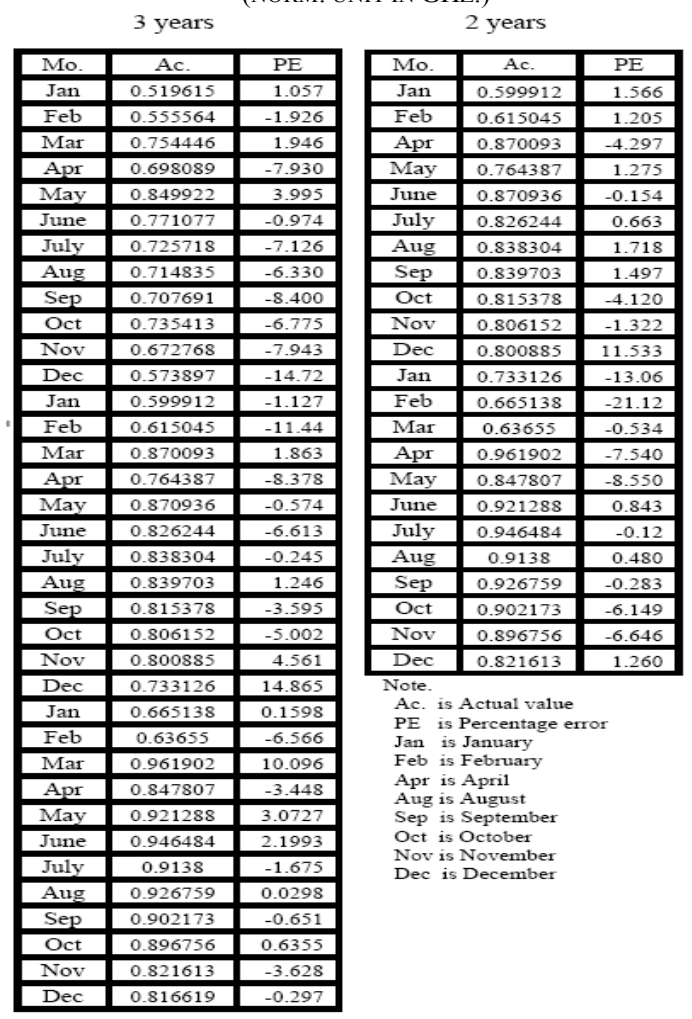


TABLE III: THE RESUltS OF FORECASTING IN EACH MODEL AND NEURON NUMBER

\begin{tabular}{|c|c|c|c|c|}
\hline \multirow{2}{*}{$\begin{array}{c}\text { Neuron bidden } \\
\text { layer }\end{array}$} & \multicolumn{2}{|c|}{ 2 years ahead } & \multicolumn{2}{c|}{ 3 years ahead } \\
\cline { 2 - 5 } & Model 1 & Model 2 & Model 1 & Model 2 \\
\hline 5 & 5.95 & 4.65 & 4.53 & 4.63 \\
\hline 10 & 6.97 & 4.17 & 4.47 & 5.01 \\
\hline 15 & 7.19 & 4.03 & 4.97 & 4.49 \\
\hline 20 & 6.10 & 4.24 & 4.88 & 4.53 \\
\hline 25 & 6.79 & 4.43 & 4.84 & 4.65 \\
\hline 30 & 6.09 & 4.37 & 4.55 & 4.62 \\
\hline Average & 6.51 & 4.35 & 4.70 & 4.65 \\
\hline
\end{tabular}

\section{CONCLUSION}

This paper presents the yearly mid-term load forecasting using artificial neural network based on feed forward back propagation algorithm in Thailand. We proposed two models forecasting: two years ahead and three years ahead demand forecasts. Two years ahead midterm load forecasting have two patterns model like model no.1 and model no.2. The model no. 1 has four inputs and model no. 2 has twelve inputs. Three years ahead midterm load forecasting have two pattern models like model no. 1 and model no. 2 which model no. 1 has four inputs and model no. 2 has four inputs similarity. Forecasts model can be varied number of neuron in hidden layer five, ten, fifteen, twenty, and thirty neurons. The results show two years ahead mid-term load forecasting model no. 2 can be reduced error. Mean Absolute Percentage Error (MAPE) in this model is $4.35 \%$. In three years ahead mid-term load forecasting model no. 1 and no.2 MAPE is almost equal, MAPE is about $4.65 \%$ and $4.70 \%$ respectively. The experimental results show two and three years ahead mid-term load forecasting by using differential models and varied number of neuron in hidden layer for finding the minimum MAPE of each model. This load demand forecast is useful for fuel reserve planning and unit commitment in the power system.

\section{ACKNOWLEDGEMENT}

The author would like to thank Generating Electricity Authority of Thailand, Meteorological department, and Ministry of Commerce Thailand for providing the electric load, weather, and economic data for using in this research.

\section{REFERENCES}

[1] S.H.Ling, Frank H.F.Leung, H.K.Lam, and Peter K.S. Tam, "Short-term electric load forecasting based on a neural on a neural fuzzy network," IEEE Trans. Ind. Electron., vol.50, no.6, Dem.2003.

[2] Zanab H.Osman, Mohamed L.Awad and Tawfik K.Mahmoud, "Neural network based approach for short term load forecasting," IEEE/PES Power systems conference and exposition, pp.1-8, March 2009.

[3] Zhang Xing-ping, and Yuan Jia-hai, "Electricity consumption forecasting based on improved BP neural network," International conference on risk management \& engineering management, pp.357-360, Nov.2008.

[4] George J.Tsekouras, Nikos D.Hatziargyriou, Evangelos N.Dialynas, "An optimized adaption neural network for annual midterm energy forecasting," "An annual midtem energy forecasting model using fuzzy logic," IEEE Trans. Power Syst., vol.21, no.1, Feb. 2006.

[5] P.K.Dash, S.Mishra, S.Dash, A.C.Liew, "Genetic optimization of a self organizing fuzzy-neural network for load forecasting," IEEE 2000.

[6] Ummuhan basaran filik,Mehmet kurban, "A new approach for the short term load forecasting with autoregressive and artificial neural network models," International journal of computational intelligence research, vol.3, no.1, pp.66-71.

[7] Jian-Chang Lu, Dong-xiao niu, zheng - yuan jia, "A study of short term load forecasting based on arima-ann," Machine Learning and Cybernetics, Volume 5, pp.3183 - 3187 vol.5, August 2004.

[8] Howard Demuth, Mark Beale, and Martin hagan, " Neural Network Toolbox ${ }^{\mathrm{TM}} 6$ User's Guide," The MathWork.,Inc.

[9] Pituk Bunnoon, Kusumal Chalermyanont, and Chusak Limsakul, "Mid Term Load Forecasting of the Country Using Statistical Methodology: Case study in Thailand," 2009 International Conference on Signal Processing System, pp.924-928, May 2009.

[10] Gwo-ching liao, Ta-peng tsao, "Integrated genetic algorithm/Tabu search and neural fuzzy networks for short-term load forecasting," Power Engineering Society General Meeting, vol.1, pp.1082 - 1087, June 2004

[11] Gwo-ching liao, Ta-peng tsao, "Novel GA-Based Approach and Neural fuzzy networks application in short-term load forecasting," Power Engineering Society General Meeting, vol.1, pp.589-594, June 2004.

[12] Kyung-Bin Song et al., "Hybrid load forecasting method with analysis of temperature sensitivities," IEEE Trans. Power Syst., vol.21, no.2, pp.869-876, May 2006.

[13] Bo-Juen Chen, Ming-Wei Chang, and Chih-Jen Lin, "Load forecasting using support vector machines: A study on EUNITE competition 2001," IEEE Trans. Power Syst., vol.19, no.4, pp.1821-1830, nov.2004.

[14] Shu Fan, Kittipong Methaprayoon, and Wei-Jen Lee, "Mutiregion load forecasting for system with large geographical area," IEEE Trans. Ind. Appl., vol.45, no.4, July/August 2009.

[15] James W. Taylor and Roberto Buizza, "Neural network load forecasting with weather ensemble predictions," IEEE Trans. Power Syst., vol.17, no.3, Aug.2003.

[16] Shu Fan, Luonan Chen, and Wei-Jen Lee, "Short-term load forecasting using comprehensive combination based on multimeteorological information," IEEE Trans. Ind. Appl., vol.45, no.4, July/August 2009.

[17] Kyung-Bin Song, Young-Silk Baek, Dug-Hun hong, and Gilsoo Jang, "Short-term load forecasting for the holidays using fuzzy linear regression method," IEEE Trans. Power Syst., vol.20, no.1, Feb.2005.

[18] Alireza Khotanzad et al., "ANNSTLF-A neural-network-based electric load forecasting system," IEEE Trans. Neural Netw., vol.8, no.4, July 1997.

[19] Gwo-Ching Liao, and Ta-Peng Tsao, "Application of a fuzzy neural network combined with a chaos genetic algorithm and simulated annealing to short-term load forecasting," IEEE Trans. Evol. Comput., vol.10, no.3, June 2006.

[20] A. Escobar M and L.P.Perez, "Application of support vector machines and ANFIS to the short-term load forecasting," IEEE/PES Transmission and distribution conference and exposition, pp.1-5, Aug. 2008.

[21] P.bunnoon, K.Chalermyanont, and C.Limsakul, "The comparision of midterm load forecasting between multi-regional and whole country area using artificial neural network," International Journal of Computer and Electrical Engineering, vol.2, pp.338-343. 